Gut, 1986, 27, 411-417

\title{
Effect of clindamycin on the ability of a continuous culture of colonic bacteria to ferment carbohydrate
}

\author{
C A EDWARDS, B I DUERDEN AND $N$ W READ \\ From the Departments of Medical Microbiology and Physiology, University of Sheffield, Sheffield
}

SUMmARY A continuous culture model of the proximal colon was used to study the effect of clindamycin on the ability of colonic bacteria to ferment carbohydrate. Six steady state anaerobic cultures of human faeces, in a medium simulating ileostomy effluent, were treated with $26 \mu \mathrm{g} / \mathrm{ml}$ clindamycin. They were paired with six untreated cultures, run under identical conditions. Clindamycin treatment eliminated the anaerobic bacteria, significantly decreased osmolality and the output of volatile fatty acids, particularly propionic acid and increased the residual carbohydrate concentration. Doubling the amount of carbohydrate in the medium increased osmolality and the production of volatile fatty acid, though the response of clindamycin treated cultures was less than that of untreated cultures. Attempts to introduce Clostridium difficile into three pairs of cultures were successful in only two cultures after administration with clindamycin and when a heavy inoculum $\left(10^{6}-10^{9}\right.$ organisms $)$ had been used.

Diarrhoea is an important side effect of the administration of broad spectrum antibiotics. In recent years, ideas concerning the mechanism of antibiotic associated diarrhoea have centred on the opportunist colonisation of the colon with Clostridium difficile. ${ }^{1}$ This organism, however, is responsible for only one third of the cases of antibiotic associated diarrhoe $\mathrm{a}^{23}$ and has been recovered in large numbers from healthy infants and some healthy adults. An alternative theory is that the reduction in anaerobic colonic bacteria by antibiotics may impair the absorption of carbohydrates by reducing their fermentation of volatile fatty acids ${ }^{4}$ which are rapidly absorbed. ${ }^{56}$ The unfermented sugars would not be absorbed and would retain fluid in the colonic lumen by virtue of their osmotic activity, resulting in osmotic diarrhoea.

We have developed a simple bacteriological model of the proximal colon, in which faecal material from normal subjects was cultured in a medium based on the composition of ileostomy effluent for long periods of time under anaerobic conditions and constant $\mathrm{pH}$ in a continuous flow system. ${ }^{7}$ The aim of this study was to investigate the effect of clindamycin on the fermentation of carbo-

Address for correspondence: N W Read, Clinical Research Unit, Royal Hallamshire Hospital, Sheffield S10 2JF.

Received for publication 5 July 1985. hydrates in our model; six cultures were treated with clindamycin and the bacterial survival and yield of volatile fatty acids was monitored. $C$ difficile was also introduced into the cultures to ascertain whether pretreatment with clindamycin enabled the organism to become established in culture.

\section{Methods}

PROXIMAL COLON MODEL

The apparatus comprised a Gallenkamp modular fermenter (model FBL, London) with some adaptations (Fig. 1). An inoculum of $20-50 \mathrm{~g}$ of fresh human faeces was homogenised in $250 \mathrm{ml}$ of prereduced sterile medium and placed in a one litre fermentation vessel (A) within one hour of collection. The medium was based on established knowledge of ileostomy effluent ${ }^{8}$ and consisted of $60 \mathrm{mmol} \mathrm{NaCl}, 40 \mathrm{mmol} \mathrm{NaHCO} 3,10 \mathrm{mmol} \mathrm{KCl}$, $10 \mathrm{~g} / \mathrm{l}$ tryptone (Oxoid), $5 \mathrm{~g} / \mathrm{l}$ porcine bile extract (Sigma), $5 \times 10^{-5} \mathrm{~g} / 1$ hemin, $1.2 \mathrm{~g} / 1 \mathrm{starch}, 5 \mathrm{~g} / 1$ glucose, $6 \mathrm{~g} / 1$ maltose. The sugars and hemin were sterilised by filtration and then mixed aseptically with the rest of the medium which had been autoclaved at $1.03 \times 10^{5} \mathrm{~Pa}$ at $121^{\circ} \mathrm{C}$ for 20 minutes. Thirteen millilitres of fresh medium was introduced over a period of two minutes every hour and excess culture was simultaneously removed by the same peristaltic pump (B), maintaining the culture 


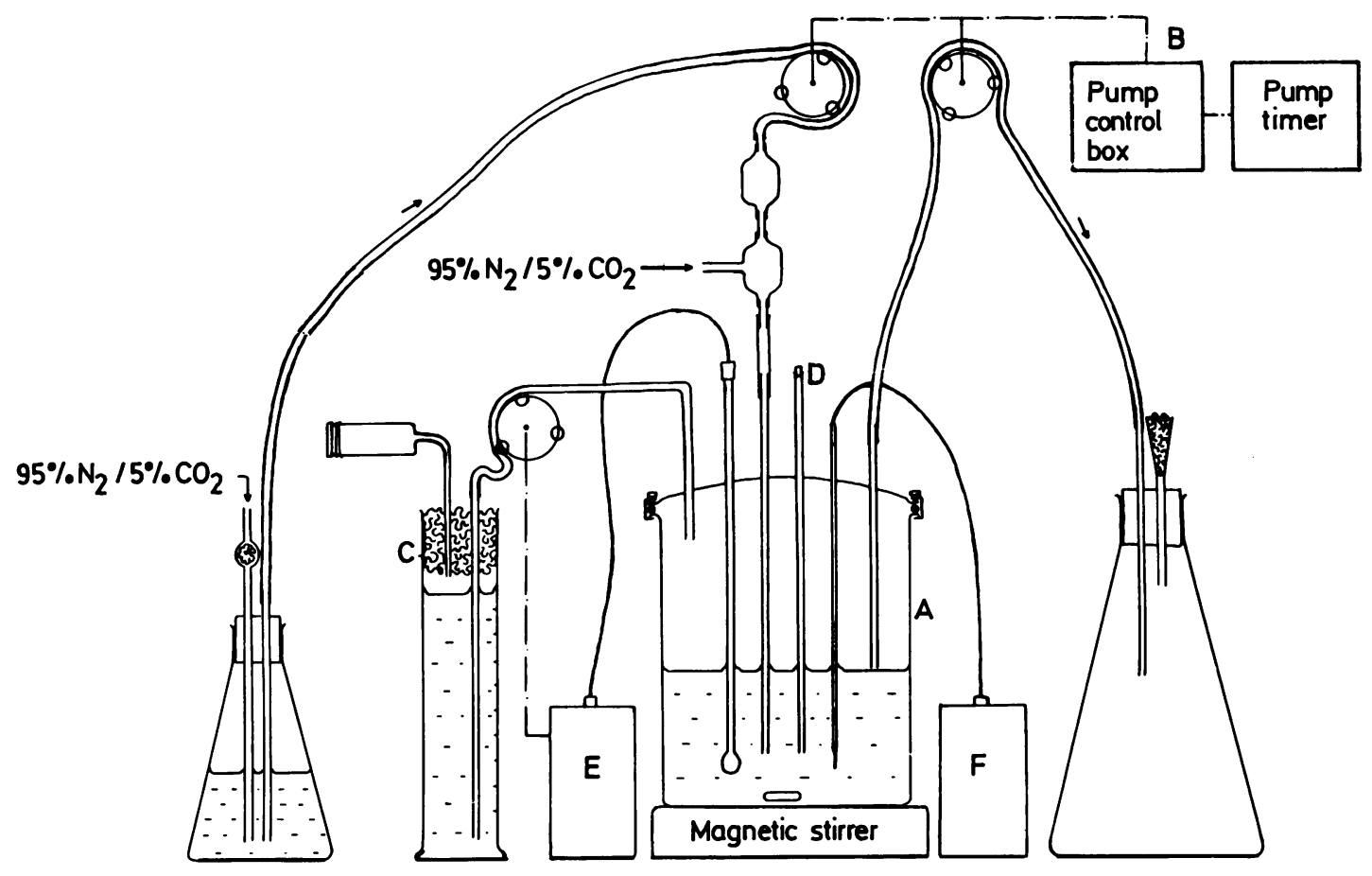

Fig. 1 Apparatus for the continuous culture of human faecal bacteria. A is the one litre fermentation vessel; $B$ is the peristaltic pump and timing device for the infusion of medium and removal of excess culture; $C$ is the $p H$ control unit which infused $\mathrm{NaHCO}_{3}$ when necessary; $D$ is the sample tube; $E$ is the $\mathrm{pH}$ meter and $\mathrm{F}$ is the electrometer used to measure Eh.

volume constant at $300 \mathrm{ml}$. Anaerobic conditions were attained by gassing the medium and fermentation vessels with $95 \% \mathrm{~N}_{2} / 5 \% \mathrm{CO}_{2}$ and by using tubing which was impermeable to gases (butyl XX tubing Esco (Rubber) Ltd, Middlesex). Hydrogen ion concentration was controlled by a $\mathrm{pH}$ stat unit (C) which infused 1.5 mol- $\mathrm{NaHCO}_{3}$ when necessary. The cultures were stirred magnetically at $100 \mathrm{rev} / \mathrm{min}$ and the whole apparatus was housed in a constant temperature room at $37^{\circ} \mathrm{C}$. Daily $20 \mathrm{ml}$ samples were taken with a $60 \mathrm{ml}$ catheter syringe through the glass sample tube (D).

\section{CHEMICAL ASSAYS}

The $\mathrm{pH}$ and redox potential (Eh) of the culture were monitored daily with a $\mathrm{pH}$ glass combination electrode (Gallenkamp, London) and an Eh platinum combination electrode (Russell CM RPT, Fife, Scotland), connected to a pH meter (FBL 20, Gallenkamp) (E) and high impedence electrometer (model 602, Keithley, Cleveland, OH) (F) respectively.

Volatile fatty acid concentrations were measured using a gas chromatograph (no 3700 Varian, Palo
Alto, CA) fitted with a 2 metre column of $4 \mathrm{~mm}$ internal diameter, packed with $10 \%$ AT 1200 and $1 \%$ $\mathrm{H}_{3} \mathrm{PO}_{4}$ on chromosorb WAW (80-100 mesh). Column temperature was $121^{\circ} \mathrm{C}$ and gas flow rates were air $300 \mathrm{ml} / \mathrm{min}, \mathrm{H}_{2} 30 \mathrm{ml} / \mathrm{min}$ and $\mathrm{N}_{2} 30$ $\mathrm{ml} / \mathrm{min}$. The samples $(3 \mu \mathrm{l})$ included an internal standard of valeric acid. External standards of acetic, propionic, n-butyric and valeric acids were used to calibrate the responses. The output of the flame ionisation detector was processed by a Hewlett Packard integrator (model 3390 MA), which integrated the areas under the peaks.

Osmolality was measured by depression of the freezing point in an osmometer (model no 3WII, Advanced Instruments, MA).

The carbohydrate concentration of the cultures was assayed by hydrolysis with $0.5 \mathrm{~mol}$ sulphuric acid, followed by incubation with glucose oxidase for one hour at $37^{\circ} \mathrm{C}$. Solutions were read at $420 \mathrm{~nm}$ on a spectrophotometer (Pye Unicam no SP6-550).

\section{BACTERIAL IDENTIFICATION}

Daily samples from the cultures were used to inoculate a series of selective and non-selective 
media for the identification of facultative and anaerobic organisms. Blood agar, Sabouraud agar (Oxoid) and MacConkey agar (Oxoid) plates were incubated aerobically at $37^{\circ} \mathrm{C}$ for 48 hours. Blood agar (Oxoid), Rogosa agar (Oxoid), reinforced Clostridial medium (Oxoid) with cotton blue, ${ }^{9}$ BM-Kanamycin $^{10}$ and BM-Kanamycin/Vancomycin, and cycloserine cefoxitin fructose agar $(\text { CCFA })^{11}$ were incubated anaerobically at $37^{\circ} \mathrm{C}$ for 48 hours in a Whitley anaerobic jar (Don Whitley Scientific, Shipley, W. Yorkshire, England) with an atmosphere of $90 \% \mathrm{H}_{2} / 10 \% \mathrm{CO}_{2}$ using an evacuation replacement method. ${ }^{12}$ After 48 hours, representative colonies of each type were subcultured. These were then identified according to colony morphology, cell morphology and a variety of conventional tests. ${ }^{13-15}$

The numbers of different bacteria were estimated in a semi-quantitative manner using a standard loop plating technique and a scoring system of $0-5$. A score of 1 was gained if the organism grew in the pool equivalent to approximately $10^{4}$ colony forming units $/ \mathrm{ml}$, a score of 2 if it appeared in the first set of streaks and so on to $5\left(>10^{8}\right.$ colony forming units $/ \mathrm{ml})^{16}$

\section{EFFECT OF CLINDAMYCIN ON CARBOHYDRATE FERMENTATION}

Six cultures were allowed to reach steady state for at least seven days before clindamycin was administered in three $8 \mathrm{mg}$ bolus doses every day at 0900 , 1400 , and 1800 for periods of 5-21 days. We used this dose of clindamycin on the assumptions that $10 \%$ of an oral dose of clindamycin reaches the colon $^{17}$ and that the chyme flow rate to the colon is $1500 \mathrm{ml} /$ day. ${ }^{18}$ As our cultures had a flow rate of approximately $300 \mathrm{ml} /$ day we used $1 / 50$ of a normal oral dose of $1200 \mathrm{mg} /$ day divided into three bolus injections. Two cultures were maintained at $\mathrm{pH} 7$ and four at $\mathrm{pH} 6$. Each culture was paired with an untreated control culture, which was seeded with the same inoculum and run under the same conditions.

In three pairs of cultures the starch, maltose, and glucose components of the medium were doubled after steady state had been reached at least five days after the clindamycin treatment was started.

INOCULATION WITH C DIFFICILE

In another three sets of paired cultures, an inoculum of $4 \times 10^{3}$ to $1.4 \times 10^{9}$ organisms (determined by the spread plate method ${ }^{19}$ from an overnight broth culture of $C$ difficile was introduced after steady state had been maintained for at least five days. Samples from the cultures were monitored for the survival of the $C$ difficile, and if no survival occurred the conditions were altered to favour survival; the size of the clostridial inoculum was increased, the $\mathrm{pH}$ was changed from 6 to 7 , the treatment with clindamycin was terminated, and ampicillin was used in an attempt to suppress Streptococcus faecalis which has been reported to inhibit the growth of $C$ difficile. ${ }^{20}$ Cultures were monitored for the establishment of $C$ difficile for at least three days after each inoculation. Each pair of cultures was used for more than one inoculation of $C$ difficile.

\section{Results}

REDOX POTENTIAL

The redox potential of all control cultures was maintained at a value more negative than $-270 \mathrm{mV}$,

Table 1 Metabolic indices of six continuous cultures of faecal organisms treated with clindamycin and six control cultures tested in parallel

\begin{tabular}{|c|c|c|c|c|c|c|}
\hline \multirow[b]{2}{*}{ Parameter } & \multicolumn{2}{|c|}{ Results of test cultures } & \multirow[b]{2}{*}{$P$} & \multicolumn{3}{|c|}{ Results of control cultures during same period } \\
\hline & $\begin{array}{l}\text { Preliminary } \\
\text { control } \\
\text { period }\end{array}$ & $\begin{array}{l}\text { During } \\
\text { clindamycin } \\
\text { treatment }\end{array}$ & & $\begin{array}{l}\text { Preliminary } \\
\text { control } \\
\text { period }\end{array}$ & $\begin{array}{l}\text { in parallel } \\
\text { with treatment } \\
\text { period }\end{array}$ & $P$ \\
\hline Redox potential (mV) & $-388 \pm 24$ & $-378 \pm 24$ & NS & $-373 \pm 13$ & $-364 \pm 15$ & NS \\
\hline Osmolality (mmol/kg) & $500 \pm 34$ & $457 \pm 44$ & $<0.05$ & $472 \pm 34$ & $456 \pm 29$ & NS \\
\hline Acetic acid output (mmol/day) & $17 \cdot 9 \pm 3 \cdot 0$ & $14 \cdot 3 \pm 1 \cdot 1$ & $<0.01$ & $17 \cdot 2 \pm 2 \cdot 2$ & $18 \cdot 5 \pm 3 \cdot 5$ & NS \\
\hline $\begin{array}{l}\text { Propionic acid output } \\
(\mathrm{mmol} / \text { day })\end{array}$ & $11 \cdot 6 \pm 2 \cdot 3$ & $0 \cdot 86 \pm 0 \cdot 3$ & $<0.001$ & $13 \cdot 8 \pm 1 \cdot 8$ & $15 \cdot 1 \pm 1 \cdot 7$ & NS \\
\hline $\begin{array}{l}\text { n-Butyric acid output } \\
\text { (mmol/day) }\end{array}$ & $2 \cdot 0 \pm 0 \cdot 8$ & $0 \cdot 4 \pm 0 \cdot 2$ & NS & $1 \cdot 0 \pm 0.4$ & $0.9 \pm 0.5$ & NS \\
\hline $\begin{array}{l}\text { Total volatile fatty acid output } \\
\text { (mmol/day) }\end{array}$ & $32 \cdot 1 \pm 2 \cdot 7$ & $15 \cdot 3 \pm 1 \cdot 0$ & $<0.001$ & $32 \cdot 5 \pm 1 \cdot 0$ & $34 \cdot 1 \pm 2 \cdot 4$ & NS \\
\hline $\begin{array}{l}\text { Residual carbohydrate } \\
\text { concentration }(\mathrm{g} / \mathrm{l})\end{array}$ & $0.00 \pm 0.00$ & $0 \cdot 70 \pm 0 \cdot 3$ & $<0.05^{*}$ & $0.03 \pm 0.03$ & $0.06 \pm 0.06$ & NS \\
\hline
\end{tabular}

Results are expressed as Mean \pm SEM. Statistical significance by Student's $t$ test. Four samples were analysed at each stage for each culture. *Wilcoxon's rank sum test. 
a level suitable for the growth of anaerobic bacteria. Neither the addition of clindamycin nor doubling the carbohydrate input (in treated or untreated cultures) produced any consistent change in the redox potential (Table 1).

\section{OSMOLALITY}

The osmolality of normal sterile medium was $285 \mathrm{mmol} / \mathrm{kg}$. After steady state had been attained, cultures at $\mathrm{pH} 7$ had an average osmolality of between $532-588 \mathrm{mmol} / \mathrm{kg}$ and those at $\mathrm{pH} 6 \mathrm{had}$ an average osmolality of $404-441 \mathrm{mmol} / \mathrm{kg}$. The osmolality of four out of six cultures (three at $\mathrm{pH} 6$ and one at $\mathrm{pH} 7$ ) decreased after clindamycin was administered $(\mathrm{p}<0 \cdot 05)$.

Clindamycin also affected the response of the osmolality to an increase in carbohydrate (Fig. 2).

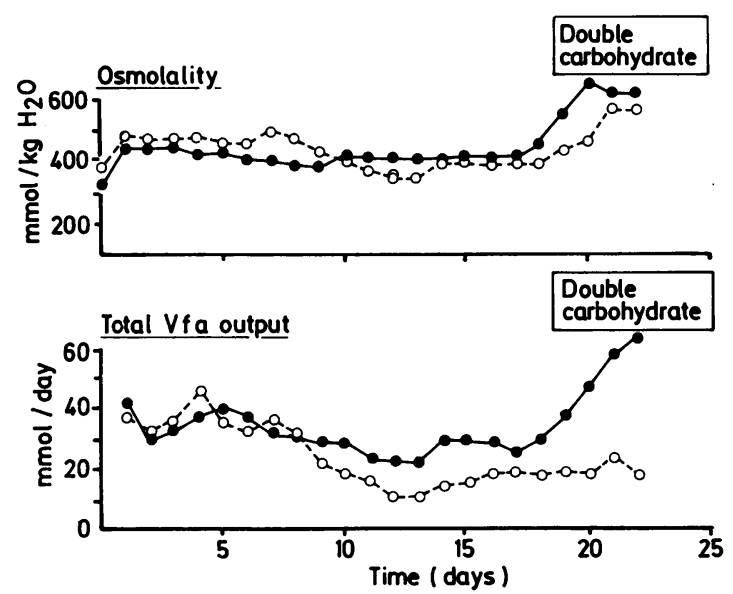

Fig. 2 Osmolality and total volatile fatty acid ( $v f a)$ profiles of a typical control culture (-1-) and a paired clindamycin treated culture (-O-O-O-) before and after the carbohydrate supply was doubled. The box indicates the period when the carbohydrate supply was doubled. The clindamycin was added to the treated culture on day seven.
The osmolality of all three cultures increased when the carbohydrate input was doubled, by $56-250 \mathrm{mmol} / \mathrm{kg}(14-60 \%)$ in control cultures and by $47-141 \mathrm{mmol} / \mathrm{kg}(14-36 \%)$ in clindamycin treated cultures. In each pair, the increase was higher in the untreated cultures. In all except one culture, the rise in osmolality was greater than that caused by the presence of the extra carbohydrate $(50 \mathrm{mmol} / \mathrm{kg})$.

\section{VOLATILE FATTY ACID PRODUCTION}

The mean total volatile fatty acid production of control cultures $(32 \cdot 5 \pm 1 \cdot 0 \mathrm{mmol} / \mathrm{day}$, mean $\pm \mathrm{SEM})$, was similar to that in the test cultures before addition of clindamycin $(32 \cdot 1 \pm 2 \cdot 7 \mathrm{mmol} /$ day $)$. After clindamycin treatment total volatile fatty acid production fell to $15 \cdot 3 \pm 1.0 \mathrm{mmol} /$ day which was significantly lower than the level maintained in the control cultures (Table 1) or in the same cultures before addition of clindamycin $(\mathrm{p}<0 \cdot 001)$. This reduction was largely caused by a decrease in the output of propionic acid from $11.6 \pm 2.3 \mathrm{mmol} /$ day to $0.9 \pm 0.3$ $\mathrm{mmol} / \mathrm{day}(\mathrm{p}<0.001)$. The effect of clindamycin on acetic acid production was variable; in four cultures, (three at $\mathrm{pH} 6$ and one at $\mathrm{pH}$ 7) the output was decreased, whereas it increased in the two cultures in which the osmolality had not declined after clindamycin treatment. Clindamycin also abolished the production of n-butyric acid in the three cultures in which it was produced. In control cultures, production of $n$-butyric acid declined but did not disappear as the culture was maintained.

When the carbohydrate input was doubled, volatile fatty acid output increased in all three control cultures (by $30-125 \%$ ) and in two of the clindamycin treated cultures (Fig. 2). This was mainly caused by an increase in acetic acid output in both cases. The average increase in total volatile fatty acid output in the clindamycin treated cultures $(5 \cdot 3 \pm 3 \mathrm{mmol} / \mathrm{day})$ was less than that in the control cultures $(22.0 \pm 6$ $\mathrm{mmol} / \mathrm{day}$ ) (Table 2) but the result was not statistically significant.

Table 2 Effect of an increase in carbohydrate input on three control and three clindamycin treated continuous cultures of human faeces.

\begin{tabular}{|c|c|c|c|c|}
\hline Parameter & $\begin{array}{l}\text { Results of un } \\
\text { Basal } \\
\text { conditions }\end{array}$ & $\begin{array}{l}\text { d cultures } \\
\text { Double } \\
\text { carbohydrate }\end{array}$ & $\begin{array}{l}\text { Results of cli } \\
\text { Basal } \\
\text { conditions }\end{array}$ & $\begin{array}{l}\text { treated cultures } \\
\text { Double } \\
\text { carbohydrate }\end{array}$ \\
\hline Redox potential (mV) & $-347 \pm 8$ & $-377 \pm 30$ & $-365 \pm 13$ & $-379 \pm 25$ \\
\hline Osmolality $\left(\mathrm{mmol} / \mathrm{kg} \mathrm{H}_{2} \mathrm{O}\right)$ & $427 \pm 9$ & $600 \pm 40$ & $368 \pm 17$ & $471 \pm 46$ \\
\hline $\begin{array}{l}\text { Total volatile fatty acid output } \\
\text { (mmol/day) }\end{array}$ & $30 \cdot 3 \pm 4 \cdot 5$ & $42 \cdot 4 \pm 5 \cdot 2$ & $15 \cdot 5 \pm 2 \cdot 6$ & $18 \cdot 8 \pm 3 \cdot 0$ \\
\hline Acetic acid output (mmol/day) & $14 \cdot 1 \pm 1 \cdot 5$ & $25 \cdot 0 \pm 4 \cdot 0$ & $15 \cdot 2 \pm 2 \cdot 6$ & $18 \cdot 4 \pm 3 \cdot 2$ \\
\hline Propionic acid output (mmol/day) & $15 \cdot 9 \pm 3 \cdot 1$ & $15 \cdot 9 \pm 2 \cdot 5$ & $0 \cdot 3 \pm 0 \cdot 2$ & $0 \cdot 3 \pm 0 \cdot 1$ \\
\hline Residual carbohydrate concentration $(\mathrm{g} / \mathrm{l})$ & $0 \cdot 22 \pm 0 \cdot 22$ & $1 \cdot 26 \pm 1 \cdot 07$ & $1 \cdot 51 \pm 0 \cdot 78$ & $3 \cdot 67 \pm 1 \cdot 31$ \\
\hline
\end{tabular}

Results are expressed as Mean \pm SEM. 
CARBOHYDRATE CONCENTRATION

The carbohydrate concentration of the cultures under basal conditions was very low (undetectable in most cases) (Table 1). After administration of clindamycin the level rose in every case $(p<0.05)$. In those cultures where the carbohydrate supply was doubled, the carbohydrate concentration of the clindamycin cultures rose further and reached higher levels than were present in the untreated cultures under the same conditions (Table 2). The difference was, however, not statistically significant.

\section{BACTERIA}

Before administration of clindamycin the cultures supported a range of bacterial species (Table 3), which resembled that found in the original inocula. Most species, Escherichia coli, Klebsiella spp., Str faecalis and Bacteroides spp either retained their original populations or increased in number while grown in culture. Some species, Clostridium spp and diptheroids maintained their population or decreased in number. The lactobacilli and bifidobacteria were not detected in any culture after three days. Each culture contained three or four species of bacteroides, usually from the $B$ fragilis group, and the Clostridium species present were $C$ perfringens and $C$ septicum. $C$ difficile was not found in any of the original inocula nor did it spontaneously appear in any culture.

Treatment with clindamycin eliminated or considerably reduced the anaerobes, though some Bacteroides spp ( $B$ vulgatus and $B$ variabilis) gradually re-established themselves seven to 13 days after the start of the clindamycin treatment. When tested, these were found to be resistant to clindamycin up to a concentration of $0.8 \mathrm{mg} / \mathrm{ml}$. There was no consistent effect of clindamycin on the other bacteria (Table 3), though the numbers of at least one facultative species increased after clindamycin treatment. Klebsiella spp increased in four cultures and Str faecilis increased in three. $C$ difficile did not appear in any culture after administration of clindamycin.

When the carbohydrate supply of the cultures was doubled, there was no consistent change in most bacterial species. The exception was $E$ coli which gained higher scores in all three cultures. This increase in $E$ coli population did not occur in any of the clindamycin treated cultures.

\section{INOCULATION WITH C DIFFICILE}

Seven attempts were made to establish $C$ difficile in control and in clindamycin treated cultures. Three sets of paired cultures were used. Inoculation with $4 \times 10^{3}$ organisms and $3 \times 10^{4}$ organisms did not result in growth of the organisms, whether the $\mathrm{pH}$ was maintained at $\mathrm{pH} 6$ or $\mathrm{pH} 7$. Because the concentration of clindamycin was above the minimal inhibitory concentration for $C$ difficile, ${ }^{21}$ clindamycin treatment was discontinued in the next set of cultures before inoculation with $4.5 \times 10^{6}$ organisms. Recovery of $C$ difficile was achieved at a score of one in the culture that had been treated with clindamycin.

Finally, in the third experiment the cultures were pretreated with ampicillin at two doses $(10 \mu \mathrm{g} / \mathrm{ml}$ and $30 \mu \mathrm{g} / \mathrm{ml}$ ) to inhibit the Str faecalis which is reported to suppress the growth of $C$ difficile in vitro ${ }^{20}$ the clindamycin was discontinued and the culture was inoculated with $1.4 \times 10^{9}$ organisms. The ampicillin had no effect on either the clindamycin treated culture or the control culture. $C$ difficile was recovered for three days after inoculation and on the final day isocaproic acid, which is produced by $C$ difficile and was not previously present, was detected in the culture fluid. $C$ difficile was never recovered from cultures that had not been treated with clindamycin.

Table 3 Effect of $26 \mu \mathrm{g} / \mathrm{ml}$ clindamycin on the mean scores gained by bacterial species in six continuous cultures of faecal bacteria

\begin{tabular}{|c|c|c|c|c|c|c|c|c|c|c|c|c|}
\hline \multirow[b]{2}{*}{ Bacterial species } & \multicolumn{12}{|c|}{ Mean score gained by bacterial in individual cultures during } \\
\hline & 1 & 2 & 3 & 4 & $5^{*}$ & $6^{*}$ & 1 & 2 & 3 & 4 & $5^{*}$ & $6^{*}$ \\
\hline E coli & 2 & 3 & 3 & 4 & 3 & 4 & 3 & 4 & 3 & 4 & 3 & 3 \\
\hline Klebsiella spp & 2 & 1 & 0 & 4 & 0 & 3 & 3 & 3 & 1 & 4 & 2 & 3 \\
\hline Proteus spp & 1 & 0 & 0 & 0 & 0 & 0 & 1 & 0 & 0 & 0 & 0 & 0 \\
\hline Str faecalis & 1 & 1 & 2 & 1 & 3 & 1 & 1 & 2 & 2 & 4 & 3 & 3 \\
\hline Diphtheroids & 0 & 0 & 0 & 0 & 1 & 1 & 0 & 0 & 0 & 0 & 1 & 1 \\
\hline Clostridium spp $\dagger$ & 1 & 0 & 1 & 0 & 2 & 0 & 0 & 0 & 0 & 0 & 0 & 0 \\
\hline Bacteroides spp ${ }^{\dagger}$ & 3 & 4 & 3 & 4 & 3 & 4 & 1 & 0 & 0 & 0 & 0 & 0 \\
\hline
\end{tabular}

Cultures marked ${ }^{*}$ were maintained at $\mathrm{pH} 7$, the others at $\mathrm{pH} 6 .+$ indicate anerobic species. 


\section{Discussion}

The ability of the colon to ferment unabsorbed carbohydrate is difficult to investigate because of the inaccessibility of the proximal colon, where most fermentation occurs. We have developed an in vitro model of the proximal colon, in which faecal bacteria are cultured in conditions simulating those found in the colon. This model has been used to investigate the action of clindamycin on bacterial content and metabolism.

We have attempted to mimic the environment of the proximal colon as closely as practically possible by using a medium based on ileostomy effluent, by using a faecal inoculum which contains the same types of bacteria as are present in the proximal colon $^{22}$ and by maintaining an anaerobic atmosphere. An infusion of sodium bicarbonate simulated colonic secretion of bicarbonate in the colon. The dilution rate of approximately one per day was chosen as this was successful in growing mixtures of rumen bacteria and rat colonic bacteria in continuous cultures. ${ }^{23} 24$

It is very difficult to mimic all aspects of the colonic environment, and our model differs in several important aspects. The cultures were essentially liquid unlike caecal contents which are more solid. There was little provision of bacterial attachment sites. The clearance of volatile fatty acid from the colon by absorption could not be reproduced; products of bacterial metabolism could only escape from the system via the outflow cannula. The carbohydrate supply was of simple standard sugars whereas it is known that glycoproteins, mucin and complex polysaccharides are all digested by colonic bacteria. ${ }^{25-27}$ Our cultures were unable to support populations of lactobacilli and bifidobacteria which are important components of the colonic flora. Also the scores gained by the bacteroides and enterobacteria were similar in some cultures. This is different from the situation in vivo where the anaerobes outnumber the aerobes. This result may indicate another difference between our cultures and the colon but may also be because of the insensitivity of our culture techniques. The scores gained by these groups were similar to those gained by the same bacteria in the original inoculum. Despite these considerations, our model maintained a range of bacteria from the faecal inoculum in steady populations for up to 28 days, and the cultures actively metabolised sugars to volatile fatty acids which accumulated in proportions very similar to those found in vivo. ${ }^{4}$

Treatment with clindamycin suppressed the anaerobic flora in our cultures, reduced the output of volatile fatty acid, particularly propionic acid, and reduced the ability of the cultures to increase production of volatile fatty acid in response to an increase in supply of carbohydrate. These findings were associated with an increase in the residual amount of unfermented carbohydrate in our cultures. Previous reports have shown that clindamycin suppresses the colonic anaerobic flora in vivo. ${ }^{28}$ Our results indicate that clindamycin inhibits the fermentation of carbohydrate. As appreciable quantities of carbohydrate normally enter the colon each day ${ }^{829}$ suppression of fermentation would cause carbohydrate to remain in the lumen where it could cause diarrhoea by an osmotic mechanism.

Treatment with clindamycin also changed the pattern of the volatile fatty acid profile, suppressing volatile fatty acid production by the anaerobic bacteria. Propionic acid production was almost abolished and, in the cultures in which it was produced, n-butyric acid production was also eliminated. This could be important for the metabolism of the colonic enterocytes which may use n-butyric in preference to glucose as their main energy source. ${ }^{30}$

The possibility that clindamycin treatment facilitates the growth of endogenous or exogenous $C$ difficile was not confirmed in our studies. Clindamycin treatment did not result in the appearance of $C$ difficile in any culture. Moreover, seven attempts to 'infect' clindamycin-treated cultures with $C$ difficile resulted in success only when clindamycin was discontinued and the inoculum contained a very large number of organisms. $C$ difficile was never established in untreated cultures. This suggests that factors other than the suppression of the normal flora are important for the establishment of $C$ difficile. It is possible that lack of mucosa or attachment sites may have prevented growth of $C$ difficile as attachment is often a prerequisite for pathogens. ${ }^{31}{ }^{32}$ The high dilution rate, and presence of Str faecalis may have also inhibited the establishment of $C$ difficile in the culture, though these factors might also be present in the colon of a patient with diarrhoea.

In summary, these studies have shown that clindamycin suppresses human colonic anaerobic bacteria in mixed continuous culture, reducing volatile fatty acid production and changing the pattern of volatile fatty acid produced. Similar effects occuring in vivo would compromise the ability of the colon to ferment and absorb carbohydrate and would result in diarrhoea if the patient is eating normally. This mechanism may explain why $C$ difficile cannot be implicated in many cases of antibiotic associated diarrhoea.

This work was supported by a grant from the Medical Research Council. 


\section{References}

1 Bartlett JG, Taylor NS, Chang T, Dzink J. Clinical and laboratory observation in Clostridum difficile colitis. Am J Clin Nutr 1980; 33: 2521-6.

2 Aronsson B, Mollby R, Nord CE. Occurrence of toxinproducing Clostridium difficle in antibioticassociated diarrhoea in Sweden. Med Microbiol Immunol -1981; 170: 27-35.

3 George WL, Rolfe RD, Finegold SM. Clostridum difficile and its cytotoxin in faeces of patients with antimicrobial agent associated diarrhoea and miscellaneous conditions. J Clin Microbiol 1982; 15: 1049-53.

4 Cummings $\mathrm{JH}$. Short chain fatty acids in the human colon. Gut 1981; 22: 763-79.

5 McNeil I, Cummings JH, James WPT. Short chain fatty acid absorption by the human large intestine. Gut 1978; 19: 819-22.

6 Ruppin H, Bar-meir S, Soergel KH, Wood CM, Schmitt MG. Absorption of short chain fatty acids by the colon. Gastroenterology 1980; 78: 1500-7.

7 Edwards CA, Duerden BI, Read NW. Metabolism of mixed human colonic bacteria in a continuous culture mimicking the human caecal contents. Gastroenterology 1985; 88: 1903-9.

8 McNeil NI, Bingham S, Cole TJ, Grant AM, Cummings JH. Diet and health of people with an ileostomy. 2. Ileostomy function and nutritional state. Br J Nutr 1982; 47: 407-15.

9 Willis AT, Bullen CL, Williams K, Fagg CG, Bourne A, Vignon M. Breast milk substitute. A bacteriological study. Br Med J 1973; 4: 67-72.

10 Holbrook WP, Ogston SA, Ross RW. A method for the isolation of Bacteroides melaninogenicus from the human mouth. J Med Microbiol 1978; 11: 203-7.

11 George WL, Sutter VL, Citron D, Finegold SM. Selective and differential medium for isolation of Clostridium difficile. J Clin Microbiol 1979; 9: 214-19.

12 Collee JG, Watt B, Fowler EB, Brown R. An evaluation of the Gas-Pak system in the culture of anaerobic bacteria. J Appl Bacteriol 1972; 35: 71-82.

13 Cowan ST. Manual for the identification of medical bacteria. 2nd ed. Cambridge: Cambridge University Press, 1974.

14 Willis AT. Anaerobic bacteriology, clinical and laboratory practice. 3rd ed. London: Butterworths, 1977.

15 Rotimi VO, Faulkener J, Duerden BI. Rapid method for the identification of clinical isolates of gram negative anaerobic bacilli. Med Lab Sci 1980; 37: 331-9.
16 Rotimi VO, Duerden BI. The development of the bacterial flora in normal neonates. $J$ Med Microbiol 1981; 14: 51-62.

17 Martindale. The extra pharmacopoeia 27th ed. Wade A, ed. London: The Pharmaceutical Press, 1977: 1114.

18 Phillips SF, Giller J. The contribution of the colon to electrolyte and water conservation in man. J Lab Clin Med 1973; 52: 733-46.

19 Koch AL. Growth measurement. In: Gerdhart P, ed. Manual of methods for general bacteriology. Washington, DC: The American Society for Microbiology, 1981: 187.

20 Malamou-Ladas H, Tabaqchali S. Inhibition of Clostridim difficile by faecal streptococci. J Med Microbiol 1982; 15: 569-74.

21 Shuttleworth R, Taylor M, Jones DM. Antimicrobial susceptibilities of Clostridium difficile. J Clin Pathol 1980; 33: 1002-5.

22 Moore WEC, Cato EP, Holdeman LV. Some current concepts in intestinal bacteriology. Am J Clin Nutr 1978; 31: S33-S42.

23 Czerkawski JW, Brekenridge G. Design and development of a long term rumen simulation technique (Rusitec). Br J Nutr 1977; 38: 371-84.

24 Veilleux BG, Rowland I. Simulation of the rat intestinal ecosystem using a two stage continuous culture system. J Gen Microbiol 1981; 123: 103-15.

25 Salyers AA, West SEH, Vercellotti JR, Wilkins TD. Fermentation of mucins and plant polysaccharides by anaerobic bacteria from the human colon. Appl Environ Microbiol 1977; 34: 529-33.

26 Hoskins LC, Boulding ET. Mucin degradation in human colon ecosystems. J Clin Invest 1981; 67: 163-72.

27 Perman JA, Modlers S. Glycoproteins as substrates for production of hydrogen and methane by colonic bacterial flora. Gastroenterology 1982; 83: 388-93.

28 Marr JJ, Sans MD, Tedesco FJ. Bacterial studies of clindamycin associated colitis. Gastroenterology 1975; 69: 352-58.

29 Stephen AM, Haddad AC, Phillips SF. Passage of carbohydrate into the colon. Gastroenterology 1983; 85: 589-96.

30 Roediger WEW. Role of anaerobic bacteria in the metabolisc welfare of the colonic mucosa in man. Gut 1980; 21: 793-8.

31 Candy DCA. Adhesion of bacteria to mucosal surfaces, an area of increasing importance in diarrhoeal disease. Eur J Pediatr 1980; 134: 3-8.

32 Dudley JP. Adherence of micro-organisms in infections of the respiratory tract. Laryngoscope 1982; 92: 68-9. 